\title{
Young and Old Leaves Physiological and Metabolite Profiles Analysis on Amino Acids and Organic Acids in Wild Soybean Seedlings Under Nitrogen Deficiency
}

\section{Yuan Liu}

Northeast Normal University, Ministry of Education

Shujuan Gao

Northeast Normal University, Ministry of Education

Yunan $\mathrm{Hu}$

Northeast Normal University, Ministry of Education

Tao Zhang

Northeast Normal University, Ministry of Education

Jixun Guo

Northeast Normal University, Ministry of Education

Lianxuan Shi ( $\square$ lianxuanshi@nenu.edu.cn )

Northeast Normal University, Ministry of Education

\section{Research Article}

Keywords: Wild Soybean, Low nitrogen, Metabolomics, Physiological, Amino acids, Organic acids.

Posted Date: December 8th, 2021

DOI: https://doi.org/10.21203/rs.3.rs-1142628/v1

License: (c) (i) This work is licensed under a Creative Commons Attribution 4.0 International License. Read Full License 


\section{Abstract \\ Background}

As an important germplasm resource, wild soybean has good tolerance to complex stress environment stress. This study described the differences of physiological and metabolomic changes between common wild soybean (GS1) and the barren tolerance wild soybean (GS2) under low nitrogen (LN) stress.

\section{Results}

The result showed the barren tolerance wild soybean young leaves can maintain relatively stable chlorophyll content and increased the contents of $\mathrm{Car}$,Photosynthetic rate and transpiration rate decreased significantly in in the barren tolerance wild soybean old leaves, but there was no significant change in young leaves; the barren tolerance wild soybean enhanced the enrichment of beneficial ion pairs such as zinc, calcium and phosphorus. The metabolism of amino acids and organic acids in the barren tolerance wild soybean old leaves was vigorous, a large number of beneficial amino acids such as GABA, asparagine and proline were enriched, and the metabolites related to TCA cycle were significantly increased.

\section{Conclusion}

the barren tolerance wild soybean can ensure the nitrogen supply of young leaves by inhibiting the photosynthetic response of old leaves; the relatively stable growth of young leaves also benefits from the effective transport and reuse of beneficial ions from old leaves; More importantly, the enhanced metabolism of specific amino acids and organic acids in GS2 old leaves seemed to play an important role in resisting LN stress. GABA and Asparagine played substantial roles in $\mathrm{N}$ storage, $\mathrm{C} / \mathrm{N}$ balance, antioxidant defense and act as signaling molecule to help GS2 to resist LN stress. Difference organic acids in the old leaves of GS2 increased which could improve the utilization rate of N in the soil. In addition, the strength of fatty acids catabolism and TCA cycle in GS2 old leaves provided energy base for substance transport. The analysis of physiological and metabolite may provide a new perspective for revealing the importance of substance transport and reuse in different plant parts to resist abiotic stress.

\section{Introduction}

Evaluation and identification of germplasm resources is a basic and vital problem of industrial crop improvement[1]. Compared with cultivars, crop wild relatives have been challenged in natural environments for thousands of years and are evolved to withstand various biotic and abiotic stresses [2]. Due to limited or no breeding barriers, crop wild relatives are a rational choice to improve plant traits. Wild soybean (Glycine soja) is considered as the progenitor of cultivated soybean (Glycine max.)[1]. Wild soybean maintains a much higher level of genetic diversity and harbors treasured genetic resource [3]. In the process of adapting to different natural environment, wild soybean has evolved many ecological types, such as salt alkali tolerance, drought tolerance, barren tolerance and so on [4]. Fully appreciate and comprehensive understanding the mechanism of wild soybean resources resisting adverse environment is a subject of both theoretical and practical significance.

Nitrogen $(\mathrm{N})$ is the most important factor limiting plant growth and development [5]. When plants lack of $\mathrm{N}$, the synthesis of chlorophyll content in leaves decreases, photosynthesis is weakened, growth and development is slow or stagnant [6]. Legumes seeds protein(dry weight) contain $40 \% \mathrm{~N}$ which led to a large quantities of $\mathrm{N}$ accumulation on plant throughout the growing season[7]. Biological nitrogen fixation (BNF) activity can be limited by a number of environmental conditions, especially in the seedling stage, it is more vulnerable to nitrogen deficiency [8]. Crop producers continually applying large amount of $\mathrm{N}$ fertilizer to increase soybean yield. While excessive $\mathrm{N}$ fertilization leads to environmental problems and 
adversely affected the sustainable development of agriculture. Therefore, it is very necessary and urgent to improve soybean LN tolerance through excellent Wild Germplasm resources. In recent years, metabolomics and its correlation with ion content analyses had been widely used to determine responses to various abiotic stresses, including salinity, drought and nutritional deficits $[9,10]$. Metabolomics lends insight into the deep relationship between metabolites and changes in plant physiology conditions by combining a range of different analytical technologies and calculation

methods [11]. Under the condition of nutrient deficiency, plant autophagy system and vacuolar proteinase can decompose nitrogen related macromolecular substances into amino acids, peptides and urea, and then transport them

to nitrogen demanding organs [12]. During plant leaves senescence, macromolecular compound catabolic increase, while anabolic processes decrease, and the mobilization and recycling of nutrients from old leaves to sinks, such as young leaves, especially under the condition of nutritional deficiency, in Arabidopsis thaliana have made similar reports [13].

In the process of response to abiotic stress, the accumulation of some specific metabolites such as sugars, organic acids and amino acids have been suggested to have biochemical modulation. Amino acids are important metabolites and carriers of organic nitrogen transport between plant organs [14]. Under stress conditions, Amino acids are subsequently recycled and allocated for the synthesis of specific proteins required under nutrient limitation [15]. Furthermore, during carbon or nitrogen starvation, proteins are degraded, and the complete oxidation of their amino acids produces the energy required to fuel the particular needs of stressed leaves. Furthermore, $\mathrm{N}$ uptake rates by roots of intact soybean plants is stimulated by malate, which moves down the phloem and accumulates in the root [16]. Understanding organic acid metabolism and nitrate uptake and utilization could be an important avenue to understand the survival strategies of barren tolerance wild soybean. The combined analysis of physiological and metabolite profiles will provide a new perspective for revealing the reuse of $\mathrm{N}$ between young and old leaves of legumes under the LN condition [17].

To reveal the tolerant strategies in different ecotypes wild soybean to LN stress, the common (GS1) and barren tolerance (GS2) wild soybean were subjected to LN treatment, and then the physiological and metabolomics changes were compared between low nitrogen group and control group (CK) in the two soybean ecotypes young and old leaves, respectively. The analysis of different ages leaves on the plants in order to capture different metabolite changes among young and old leaves of common wild soybean and LN-tolerant wild soybean to identify differences to survive in LN stresses. This study tries to reveal the species and characteristics of material metabolism in young and old leaves of wild soybean during resisted the LN stress. To explore the metabolic mechanism between different ages leaves under the stress. This study could provide a theoretical basis for evaluation and identification of excellent wild soybean resources and optimizing cultivated soybean varieties.

\section{Result}

\subsection{Physiological parameters}

Compared with CK, GS1 shoot height decreased more and root length increased less than that of GS2, meanwhile, the shoot dry weight (DW) and root DW were decreased in both ecotypes under LN stress compared to CK and declined even

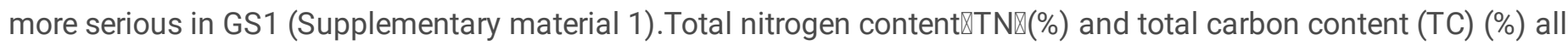
decreased in young leaves of GS1, and that of GS2 young leaves increased. The C/N ratio in GS1 young leaves increased, but decreased in GS2 young leaves. In the old leaves, TN (\%) decreased significantly in both two ecotypes wild soybean ( $P$ $<0.05)$.), especially in GS1 old leaves. TC (\%) decreased in GS1 old leaves and increased in GS2 old leaves. The C/N ratio increased significantly in GS1old leaves $(P<0.05)$, and increased highly significant in GS2 old leaves $(P<0.01)($ Fig 1$)$.

Compared with $\mathrm{CK}, P_{\mathrm{N}}$ decreased in both wild soybean young leaves under the $\mathrm{LN}$ stress, especially in $\mathrm{GS} 1 . g_{\mathrm{s}}, C_{\mathrm{i}} / C_{\mathrm{a}}$ and $E$ increased under the LN stress in two wild soybean young leaves, compared with CK, especially in GS2 young leaves which increased significantly $(\mathrm{P}<0.05)$. Chla, Chlb, Chl $(a+b)$ and Carall decreased in two wild soybeans young leaves, especially in GS1 young leaves, in which $C h l(a+b)$ decreased significantly $(\mathrm{P}<0.05)$. In two wild soybean old leaves, $P_{\mathrm{N}}$, 
$g_{\mathrm{s}}$ and $E$ all decreased under the LN stress, compared with CK. Compared with $\mathrm{CK}, C_{\mathrm{i}} / C_{\mathrm{a}}$ increased significantly in the GS1 and GS2 old leaves under the LN stress, especially in GS2 old leaves $(P<0.05)$. Chla, Chlb, Chl $(a+b)$ decreased significantly in GS1 and GS2 old leaves, especially in GS1 old leaves decreased significantly $37 \% \varangle 47 \%$ and $40 \%(P<0.05)$ (Fig.2).

\section{2 lonomic response}

According to the principal component analysis (PCA) of the ion contents in the two ecotypes wild soybeans young and old leaves (Fig.3). The ion contents PCA of young leave, CK and LN groups were clearly separated by the first component (PC1), representing $70.9 \%$ of the total variation, and $\mathrm{NO}_{3}{ }^{-}, \mathrm{SO}_{4}{ }^{2-}, \mathrm{SO}_{4}{ }^{2-}, \mathrm{Cl}^{-}, \mathrm{B}^{3+}$ and $\mathrm{Fe}^{3+}$ were the major contributors (Fig. 3A, Fig.3B, Supplementary material 2). PC2 distinguished the different ecotypes, which represented $16.9 \%$ of the variation, and $\mathrm{NO}_{3}{ }^{-}, \mathrm{Mn}^{2+}, \mathrm{Mn}^{2+}, \mathrm{H}_{2} \mathrm{PO}_{4}{ }^{-} \mathrm{P}^{5+}$ and $\mathrm{Na}^{+}$were major contributors to PC2 (Fig. 3A, Fig. 3B, Supplementary material 2). The $C K$ and $L N$ ion contents in old leaves were clearly separated by the first component (PC1), representing $58.9 \%$ of the total variation, and $\mathrm{NO}_{3}{ }^{-}, \mathrm{Mg}^{2+}, \mathrm{Ca}^{2+}, \mathrm{Cl}^{-}, \mathrm{B}^{3+}$ and $\mathrm{Fe}^{3+}$ were the major contributors (Fig. 3C, Fig. 3D, Supplementary material 2). PC2 distinguished GS1 and GS2, which represented $13.2 \%$ of the variation, and $\mathrm{H}_{2} \mathrm{PO}_{4}{ }^{-}, \mathrm{SO}_{4}{ }^{2-}, \mathrm{C}_{2} \mathrm{O}_{4}{ }^{2-}$, $\mathrm{Mn}^{2+}, \mathrm{Na}^{+}$and $\mathrm{P}^{5+}$ were major contributors to PC2 (Fig. 3C, Fig. 3D, Supplementary material 2).

Under the LN stress, compared with $\mathrm{CK}, \mathrm{NO}_{3}{ }^{-}$decreased in two wild soybeans young leaves significantly $(\mathrm{P}<0.05)$, especially in GS1 young leaves. $\mathrm{SO}_{4}{ }^{2-}$ also had a significantly drop in GS1 and GS2 young leaves $(P<0.05)$. compared with $\mathrm{CK}, \mathrm{Na}^{+}$and $\mathrm{Ca}^{2+}$ decreased in GS1 young leaves but increased significantly in GS2 young leaves. Of particular note was that the significant enrichment of $\mathrm{Mn}^{2+}$ and $\mathrm{Zn}^{2+}$ contents in GS2 young leaves was much higher than that in GS1, which had a significantly increased trend in GS1 and GS2 young leaves. The contents of $\mathrm{B}^{3+}, \mathrm{Fe}^{3+}, \mathrm{P}^{5+}, \mathrm{H}_{2} \mathrm{PO}_{4}{ }^{-}$and $\mathrm{C}_{2} \mathrm{O}_{4}{ }^{2-}$ increased significantly in GS1 young leaves $(P<0.05)$ and highly significantly in GS2 young leaves $(P<0.01)$. In response to $\mathrm{LN}$ stress, $\mathrm{NO}_{3}{ }^{-}, \mathrm{Mg}^{2+}$ and $\mathrm{Ca}^{2+}$ decreased in the two wild soybean ecotypes compared with $\mathrm{CK}^{2} \mathrm{SO}_{4}{ }^{2-}, \mathrm{C}_{2} \mathrm{O}_{4}{ }^{2-}$ and $\mathrm{K}^{+}$decreased in GS2 old leaves and increased in GS1 old leaves. Compared with CK, the contents of $\mathrm{Cl}^{-}, \mathrm{H}_{2} \mathrm{PO}_{4}{ }^{-}, \mathrm{Mn}^{2+}, \mathrm{B}^{3+}$, $\mathrm{Fe}^{3+}, \mathrm{Zn}^{2+}$ and $\mathrm{P}^{5+}$ all had an increased trend in two wild soybean old leaves compared with CK, respectively (Table 2).

\subsection{Young leaves metabolomics response}

The first principal component (PC1) explained $84 \%$ of the variance, indicating metabolic changes between GS1 and GS2 young leaves (Fig.4). The main metabolites contributing to PC1 were Alanine, 3-Aminoisobutyric acid, Lactulose, Threitol. The CK and LN stress samples of GS1 and GS2 young leaves were clearly separated by the second principal component (PC2), which represented $7.1 \%$ of the total variation. 3-Hydroxypropionic acid, 2-Hydroxypyridine, Oxalic acid, Maleic acid were the main factors contributing to PC2 (Fig.4A, Supplementary material 3: Table 3). The third principal component (PC3) explained $4.1 \%$ of the variance and the main contributors were Glucoheptonic acid, Threitol, Maleic acid, Palmitic acid (Fig.4A, Supplementary material 3: Table 3). Content of a total of 63 metabolites changed significantly under LN stress relative to $\mathrm{CK}$ in young leaves of both ecotypes (Table 3 ).

Under the LN stress, compared with CK, the amino acids metabolites relative concentration of Aspartic acid, Alanine increased significantly in young leaves of both ecotypes. the relative concentration of Asparagine, Valine, decreased significantly in GS1 young leaves and had no significantly change in GS2 young leaves. the relative concentration of Isoleucine, L-Homoserine, Proline increased significantly in GS2 young leaves $\nabla \mathrm{P}<0.05 \rrbracket$ while decreased in GS1 young leaves, meanwhile L-Allothreonine and Glycine had a opposed change. The relative concentration of some $\mathrm{N}$ contenting metabolites including GABA (4-Aminobutyric acid), Ethanolamine, Mannosamine, Sphingosine, 3Aminoisobutyric acid, 5-Aminovaleric acid, 2-Hydroxypyridine dropped significantly $₫ \mathrm{P}<0.05 \rrbracket$ in GS1 young leaves but had 
no significantly change in GS2 young leaves. Ethanolamine and Sphingosine increased in GS1 young leaves and decreased in GS2 young leaves significantly $\mathbb{P}<0.05$.

The organic acids metabolites relative concentration of Pyruvic acid, Glucoheptonic acid, Glycolic acid, Fumaric acid increased significantly in GS1 young leaves, but decreased significantly in GS1young leaves compared with CK, the relative concentration of Succinic Acids increased significantly in GS1 young leaves and had no significantly change in GS2 young leaves compared with CK, under the LN stress. The relative concentration of Gluconic acid, Lactic acid, Maleic acid, Nicotinic acid, Malonic acid increased in both two ecotypes, especially in GS2 young leaves. The relative concentration Citramalic acid, Shikimic acid, Methylmalonic acid, 3-Hydroxypropionic acid decreased significantly in both ecotypes. Compared with CK, the relative concentration of Mucic acid and Galactonic acid decreased significantly in GS1 young leaves and increased in GS2 young leaves. The relative concentration of Itaconic acid, D-Glyceric acid, Oxalic acid and Threonic acid decreased in GS2 young leaves, but only Itaconic acid and Oxalic acid had the same trend in GS1young leaves. Caffeic acid and Ferulic acid increased GS1young leaves significantly and decreased in GS2 young leaves. Salicylic acid decreased in GS1 and GS2 young leaves, especially in GS2 young leaves. The fatty acids metabolites relative concentration including Stearic acid, Palmitic acid, Linoleic acid and Linolenic acid decreased in GS1 and had an opposed trend in GS2 young leaves. Linolenic acid decreased in GS1 and GS2 young leaves, especially in GS2 young leaves (Fig.5).

\subsection{Old leaves metabolomics response}

The PC1 explained $67.1 \%$ of the variance, indicating old leaves metabolic changes between LN and CK groups. The main metabolites contributing to PC1 were L-Serine, Alpha-Linolenic acid, D-Arabitol, Threonine and L-Proline. The difference of GS1 and GS2 old leaves were clearly separated by the PC2, which represented $11.9 \%$ of the total variation. Vanillin, Neohesperidin, L-Aspartic acid, Maleic acid and L-Alanine were the main factors to PC2. Four experimental groups were well distinguished by PC3 which represented 5.5\% (Fig. 4B, Supplementary material 4: Table 4). Vanillin, Benzoic acid, Glyceric acid, Glucose 6-phosphate and D-Arabitol were the main contributor to PC3. Content of a total of 53 metabolites changed significantly under LN stress relative to CK in old leaves of both ecotypesincluding $17 \mathrm{~N}$ containing compunds and 20 organic acids (Table 4).

The amino acids metabolites relative contents of L-Proline, Glycine, Sarcosine, L-Homoserine and L-Aspartic acid decreased significantly in GS2 old leaves compared with CK, Under LN conditions, but had an opposed trend in GS2 old leaves, especially the relative contents of L-Proline and L-Aspartic acid. Beta-Alanine Sphingosine and GammaAminobutyric acid increased in GS2 but decreased in GS2, and it is noteworthy that the relative contents of GABA decreased in GS2 old leaves and increased significantly in GS2 old leaves. The relative contents of L-Alanine, LAsparagine, L-Valine, Cycloleucine, L-Isoleucine, L-Phenylalanine, L-Serine, Threonine and Ethanolamine increased in both two ecotypes especially in GS2 compared with CK, under the LN stress.

The relative contents of organic acids metabolites related with glycolysis and TCA path way including beta-D-Fructose 6phosphate, Pyruvic acid, Glucose 6-phosphate, Fumaric acid, L-Malic acid and Succinic acid increased in GS1 old leaves but beta-D-Fructose 6-phosphate and Fumaric acid decreased in GS2 old leaves compared with CK, under the LN stress. The relative contents of organic acids including L-Lactic acid, Maleic acid, Caffeic acid, Glycolic acid, Galactaric acid, Benzoic acid and Glyceric acid all increased high significantly in GS2 old leaves but the relative contents of Glycolic acid, Caffeic acid and Benzoic acid decreased in GS1 compared with CK, under the LN stress compared with CK, under the LN stress. The relative contents of Itaconic acid decreased in both ecotypes especially in GS1. Shikimic acid relative contents increased in GS1 old leaves but decreased significantly in GS2 old leaves compared with CK, under the LN stress. The relative contents of Palmitic acid, Stearic acid, Pelargonic acid and Linoleic acid decreased significantly in GS2 old leaves but increased in GS1 old leaves compared with CK, under the LN stress. The relative contents of 5-Aminopentanoic acid and Alpha-Linolenic acid had a opposed trend. The relative contents of Salicylic acid increased in both ecotypes. The 
relative contents of trans-Ferulic acid increased in GS2 old leaves but decreased in GS1 old leaves and the opposed trend occurreduan1 in Prunin (Fig.5).

\section{Disscussion}

The exploitation and utilization of germplasm is an important issue in the field of botany. In order to provide an important theoretical basis for the evaluation of plant resources, it is necessary to explore the excellent characters of wild soybean [18]. This study had checked the plants for rhizobium formation under the LN condition. The results showed that the number and weights of nodules in two wild soybean ecotypes seedling had no significant change under CK and LN condition and share a similar trend between the two ecotypes, which is consistent with the previous studies [19]. $\mathrm{N}$ deficiency inhibited the growth of two kinds of wild soybean seedlings due to the different adaptability to LN stress, the biomass of GS2 seedlings decreased more slightly than GS1 seedlings under LN conditions. The physiological and metabolites regulation of GS2 may played important role.

In this study, plant phenotypes and biomass accumulation further confirmed the LN stress could retard plant development and GS2 had a greater LN tolerance. Total carbon and total N data display a worse N deficiency in GS1 young leaves. N deficiency will destroy the chloroplast membrane and reduces the chlorophyll content [19]. Under LN stress, young and old leaves of GS2 had more slightly decline than GS1 in the photosynthetic pigment content, compare with CK, this helped GS2 maintain relatively stable assimilation function of photosynthesis in young and old leaves ([18]). The gas exchange coefficient increased in the two ecotypes and more significantly in GS2 young leaves, compared with CK. It can be seen from the results that $P_{n}, g_{s}$ and $E$ are obviously inhibited, indicating that GS2 slows down the photosynthetic rate in old leaves to reduce energy and material consumption to maintain relatively stable photosynthetic characteristics and resist LN stress.

It could be seen from the results that $\mathrm{NO}_{3}{ }^{2-}$ deficiency in GS1 leaves is more serious than that in GS2 leaves which indicated that GS2 had more advantages in the process of absorption and storage of $\mathrm{N}$ under the LN condition. According to the result, the contents of $\mathrm{SO}_{4}{ }^{2-}$ decreased high significantly in GS2 old leaves but increased in GS1 old leaves. Meanwhile it decreased more sharply in GS1 young leaves than that in GS2. It is a component of protein and amino acid and an essential element in the active center of enzymatic reaction. It also plays a certain role in the process of plant growth regulation, detoxification, defense and stress resistance. Organic sulfur can be converted into inorganic sulfur (mainly $\mathrm{SO}_{4}{ }^{2-}$ ) by protein hydrolysis, sulfate can be converted into organic sulfur by metabolism, and can be transferred to young parts for reuse [20]. The results indicated that GS2 transferred most of the sulfate from the senescent leaves to the tender tissues to alleviate the obstruction of ion imbalance to plant growth. Mineral elements have a great effect on the improvement of nitrogenase activity in the process of nitrogen reduction and fixation [21]. Previous studies have suggested that changes in availability of a single element could exert an effect on the uptake and accumulation of other elements in plants $[20,22]$. In this study the beneficial mineral ions were enrichment in GS2 old leaves which could help GS2 resist imbalance under LN stress [23].

According to the results of present study the relative contents of GABA in the young leaves of GS1 decreased significantly and increased in the young leaves of GS2. The same trend occurred in the old leaves. GABA acts as endogenous signaling molecule in plant growth and development and rapidly accumulates in plant tissue in response to several abiotic and biotic stresses [24,25]. Firstly囚under the LN stress囚although hydroxyls produced by nitrate reduction decreased, the frequency of electron carriers in the electron transport chain decreased, resulting in a significant increase in reactive oxygen species[26]. GABA plays a crucial role in scavenging of ROS generated rapidly due to disruption in intracellular redox equilibrium and hence significantly mitigates oxidative stress induced damages in plants [27]. Secondary, GABA has long been considered as an important link in $\mathrm{C}$ and $\mathrm{N}$ metabolism since GABA shunt pathway competes with the respiratory chain for SSADH $[28,29]$. Glutamic acid, the precursor of GABA, is considered to be the main form of nitrogen 
accumulation in the roots of plants. Glutamic acid Under stress environment, plants can make the nitrogen of glutamic acid flow into GABA and proline to regulate the metabolism of nitrogen, which is one of the key factors for plants to respond to external stimuli quickly[30,31]. Under the salt stress, the accumulation of GABA in Arabidopsis led to the increase of amino acids, the activity of glutamate dehydrogenase and the expression of GAD increased instantaneously, and then increased the flux of GABA shunt and other related pathways to regulate $\mathrm{C} / \mathrm{N}$ balance [32]. Under the stress circumstances, the GABA shunt may perform an cataplerotic role by providing carbon to the cycle through GABA catabolism to succinic acid [33]. Moreover, GABA is also a temporary N store compound. Glutamate to GABA conversion is increased under conditions that inhibit GIn synthesis, reduce protein synthesis, or enhance degradation [34]. Evidence also indicates that Glu and GABA are produced during protein storage and mobilization as a means of recycling Arg derived $\mathrm{N}$ and $C$ [28]. Thus, the GABA shunt may be of considerable importance in the $\mathrm{N}$ economy of plants. Therefore, the accumulation of GABA in GS2 young and old leaves was highly consistent, it can be inferred that GS2 can regulate $\mathrm{C} / \mathrm{N}$ balance, antioxidant and $\mathrm{N}$ storage by enriching GABA content to alleviate in stress[35].

Asparagine has a higher $\mathrm{N} / \mathrm{C}$ ratio than glutamine and can be used as a long-range transport and storage compound, especially in legumes [36,37]. Under the abiotic stress, the energy supply was insufficient, GS and Fd-GOGAT were inhibited, while AS was activated, and $\mathrm{N}$ assimilation proceeded towards asparagine metabolism. In this study, the relative contents of Asparagine increased in both GS1 and GS2 old leaves and decreased in GS1 young leave significantly, which indicates that $\mathrm{N}$ was transported and reused in GS2 but have no significant change in that of GS2 young leaves. Former study had proved that the increases of Asparagine concentrations suggest that will be easier in rendering $\mathrm{N}$ available for remobilization from the senescing leaves[17]. In this study, the relative content of L-homoserine and isoleucine increased significantly in young leaves but decreased in old leaves of GS2. These effective transport and utilization of these key amino acids between young and old leaves provided a relatively stable material basis for protein synthesis in the vigorous growth parts of GS2.

Organic acid metabolism is of fundamental importance at the cellular level for several biochemical pathways, including energy production, formation of precursors for amino-acid biosynthesis and at the whole plant level in modulating adaptation to the environment [38]. organic acids exuded by roots originate from the downward transport of organic acids in leaves [39]. The present results showed most of the differential organic acid (e.g. L-Lactic acid, Maleic acid, Caffeic acid, Galactaric acid, Benzoic acid and Glyceric acid) increased significantly in GS2 old leaves but no significant change in GS1 old leaves. Organic acid metabolism not only provides carbon skeletons during $\mathrm{N}$ assimilation but also has potential roles in osmotic regulation, cation balance, nutrient deficiency-related coping mechanisms and plant-microbe interactions at the root-soil interface [40]. organic acids have also been found to stimulate nitrate uptake. Nitrate uptake rates by roots of intact soybean plants is stimulated by malate, which moves down the phloem and accumulates in the root [41]. Some plants have specialized roots exude high amounts of organic acids (up to $23 \%$ of net photosynthesis), which acidify the soil and chelate metal ions around the roots, resulting in the mobilization of some micronutrients [42]. In addition, the relative contents of Palmitic acid, Stearic acid, Pelargonic acid and Linoleic acid decreased significantly in GS2 old leaves which means that an enhancement of fatty acid catabolism was happened in GS2 old leaves. The degradation of these organic acids (fatty acids $₫$ not only provides carbon skeleton for protein synthesis, but also provides sufficient energy base for $\mathrm{N}$ transport from old leaves to young leaves [43].

Urbanczyk et al. found that the contents of 2-oxoglutarate and other TCA cycle intermediates, including citrate, isocitrate, succinate, fumarate and malate, as key regulators of carbon nitrogen interaction, reduced under LN conditions [44]. In this study, the results showed that, under LN conditions, most of differential metabolites which related to glycolysis and TCA pathway had no significant change in GS2 young leaves under the LN stress. But in GS1 young leaves associated with the first stage (Energy consumption) of glycolysis, D-Fructose 6-phosphate and Glucose 6-phosphate, increased significantly in GS1 young leaves compared with CK, under the LN. The second stage of glycolysis (Generate energy) related organic metabolites including glyceric acid and pyruvic acid decreased extremely significant in GS1 young leaves [45]. Especially

Page $7 / 24$ 
in GS2 old leaves, the relative contents of glycolysis related metabolites such as D-Fructose 6-phosphate and Glucose 6phosphate decreased in GS2 old leaves and pyruvic acid increased significantly, this process indicated that GS2 old leaves reduced the energy consumption and strengthen Generating energy[46]. Meantime, the increase of L-Malic acid and Succinic acid enhanced the TCA in GS2 old leaves. Compared with GS1, the strategies of glycolysis and TCA in GS2 young leaves could save more energy in old leaves and the young leaves would maintain at a relatively stable state under LN-stress conditions [47].

\section{Conclusions}

As an important germplasm resource, wild soybean has good tolerance on stress. Barren tolerance (GS2) wild soybean has better NUE and can survive in LN environment. The advantage of LN tolerance of wild soybean is mainly attributed to the metabolic regulation and physiology. The young leaves of GS2 could maintain relatively stable chlorophyll content to keep the smooth progress of photosynthesis; the transportation of $\mathrm{SO}_{4}{ }^{2-}$ and other beneficial elements in the old leaves could alleviate the metabolism disorder of young leaves caused by ion imbalance under LN stress. In addition, GS2 old leaves the enrichment of specific nitrogen-containing compounds such as GABA and Asparagine can play a substantial role in $\mathrm{N}$ storage, $\mathrm{C} / \mathrm{N}$ balance, antioxidant defense and act as signaling molecule to help wild soybean to resist LN stress. The increase of the relative content of organic acids in the old leaves of GS2 could improve the utilization rate of N in the soil. The strength of fatty acids catabolism and TCA cycle in GS2 old leaves provided energy base for substance transport. The combined analysis of physiological and metabolite may provide a new perspective for revealing the importance of substance transport and reuse in different plant parts to resist abiotic stress.

\section{Materials And Methods}

\subsection{Plant materials and growth conditions}

The seeding of common wild soybean (GS1) and barren tolerant wild soybean (GS2) were grown in clean sand and arranged in 14-cm diameter pots with a bottom hole (2 cm in diameter), with three seeds of a single strain per pot. The seedlings were grown in an outdoor experimental field at Northeast Normal University, Changchun, Jilin. The average growth temperatures were $18.5 \pm 1.5^{\circ} \mathrm{C}$ and $26 \pm 2^{\circ} \mathrm{C}$ during the night and day, respectively, and the relative humidity was $60 \pm 5 \%$. The seedlings were germinated by irrigation with water.

\subsection{Stress treatments}

GS1 and GS2 were both randomly divided into two groups, with eight pots each: control and LN-treated. Four pots were used for measuring photosynthetic gas-exchange parameters and ion content, and the remaining four pots for metabolomics analyses in each group. The LN treatment was initiated when the seedlings' third leaves had grown. In the LN-treated group, GS1 and GS2 seeds were placed in 1/4-strength modified Hoagland's solution. Calcium and potassium were supplied by $\mathrm{CaCl}_{2} \cdot 2 \mathrm{H}_{2} \mathrm{O}$ and $\mathrm{KCl}$, respectively, at equivalent concentrations in the $\mathrm{LN}$ Hoagland's solution for two weeks. The CK was cultivated under normal conditions ( $1 \times$ Hoagland's solution).

\subsection{Measurements of photosynthetic gas-exchange parameters and ion contents}

Two weeks after the stress treatment, the photosynthetic gas-exchange parameters were determined using the old and young leaves in four pots receiving the same treatment. Similar growth characteristics were selected for the determination of the experimental parameters, and the determinations were performed three times. The gas-exchange parameters $P_{\mathrm{N}}, E$, $g_{\mathrm{s}}$ and $C_{\mathrm{i}}$ were measured at a photosynthetic radiation of $1200 \pm 50 \mu \mathrm{mol} \mathrm{C} \mathrm{C}^{-2} \mathrm{~s}^{-1}$ using a LI-6400 portable photosynthesis apparatus (LI-COR, Lincoln, NE, USA) with an open system. Briefly, $0.05 \mathrm{~g}$ dry samples were treated with $4 \mathrm{~mL}$ of deionized water at $100^{\circ} \mathrm{C}$ for $40 \mathrm{~min}$, and then centrifuged at 3,000 $\times \mathrm{g}$ for $15 \mathrm{~min}$. The supernatant was collected, and the process 
repeated twice until extracts reached $15 \mathrm{ml}$. The combined supernatants were used to determine anion concentrations by ion chromatography (DX-300 ion chromatographic system, AS4A-SC chromatographic column, CDM-II electrical conductivity detector, mobile phase: $\mathrm{Na}_{2} \mathrm{CO}_{3} / \mathrm{NaHCO}_{3}=1.7 / 1.8 \mathrm{mM}$, Dionex, Sunnyvale, $\left.\mathrm{CA}, \mathrm{USA}\right)$. The cation concentrations were determined using an atomic absorption spectrophotometer (Super 990F, Beijing Purkinje General Instrument Co. Ltd., Beijing, China).

\subsection{Metabolite profiling analysis}

For the metabolite profiling analysis, metabolites were independently extracted from GS1 and GS2 young and old leaves (100 $\pm 5 \mathrm{mg}$ of plant material), and a GC-MS analysis was performed using a one-dimensional Agilent 7890 gas chromatography system coupled with a Pegasus HT time-of-flight mass spectrometer. The data was acquired and preprocessed using the manufacturer's ChromaTOF software (versions 2.12, 2.22, 3.34, LECO, St. Joseph, MI, USA). Data analysis was performed using SIMCA-P 13.0 software package (Umetrics, Umea, Sweden).

\section{Abbreviations}

GABA: Y『aminobutyric acid, AS: asparagine synthetase, GS: glutamine synthetase, Fd-GOGAT: ferredoxin-dependent glutamate synthase, G-6-P: Glucose-6-phosphate, F-6-P: Fructose-6-phosphate, PEP: Phosphoenolpyruvate,3-PGA: 3phosphoglycerate phosphatase.

\section{Declarations}

\section{Ethics approval and consent to participate}

Not applicable.

\section{Consent for publication}

Not applicable

\section{Availability of data and material}

The datasets generated and analysed during the current study are available from the corresponding author on reasonable request.

\section{Competing interests}

The authors declare that they have no competing interests.

\section{Authors' contributions}

YL and SLX designed the research, YL, SJG and YNH performed the research, TZ and JXG provided experimental and writing assistance to $\mathrm{YL}, \mathrm{YL}$ analyzed the data, $\mathrm{YL}$ and $\mathrm{SLX}$ wrote the article. All authors reviewed the manuscript

\section{Acknowledgements}

We wish to thank National Natural Science Foundation of China and Natural Science Foundation of Jilin Province, China for supplying this work.

\section{Funding}


This work was supported by the National Natural Science Foundation of China (No. 32072012) and Natural Science Foundation of Jilin Province, China (No. 20200201134JC).

\section{References}

1. M.A. Nawaz, S.H. Yang, G. Chung, Wild Soybeans: An Opportunistic Resource for Soybean Improvement, Rediscovery Landrac. as a Resour. Futur. (2018).

2. H. Zhang, N. Mittal, L.J. Leamy, O. Barazani, B.H. Song, Back into the wild-Apply untapped genetic diversity of wild relatives for crop improvement, Evol. Appl. 10 (2017) 5-24.

3. M. Xie, C.Y.-L. Chung, M.-W. Li, F.-L. Wong, X. Wang, A. Liu, Z. Wang, A.K.-Y. Leung, T.-H. Wong, S.-W. Tong, Z. Xiao, K. Fan, M.-S. Ng, X. Qi, L. Yang, T. Deng, L. He, L. Chen, A. Fu, Q. Ding, J. He, G. Chung, S. Isobe, T. Tanabata, B. Valliyodan, H.T. Nguyen, S.B. Cannon, C.H. Foyer, T.-F. Chan, H.-M. Lam, A reference-grade wild soybean genome, Nat. Commun. 10 (2019) 1216.

4. D.S.Y.J.Z.M.X.L.L.X. Shi, Metabolomics Analysis Reveals the Salt-Tolerant Mechanism in Glycine soja, J. Plant Growth Regul. 36 (2017) 460-471.

5. G.A. Di Luca, M.M. Mufarrege, H.R. Hadad, M.A. Maine, Nitrogen and phosphorus removal and Typha domingensis tolerance in a floating treatment wetland, Sci. Total Environ. 650 (2019) 233-240.

6. M. Arun, R. Radhakrishnan, T.N. Ai, A.H. Naing, I.J. Lee, C.K. Kim, Nitrogenous compounds enhance the growth of petunia and reprogram biochemical changes against the adverse effect of salinity, J. Hortic. Sci. Biotechnol. 91 (2016) 562-572.

7. S.M.G.K.J.M.O.C.A.S.C.D.L.C.W.D.H.E.D.N.H.K.J.N.J.R.J.L.J.V.K.L.R.K.D.T.L.E.L.M. Shaun, Soybean Response to Nitrogen Application Across, (2006) 1-5.

8. S. Mourtzinis, G. Kaur, J.M. Orlowski, C.A. Shapiro, C.D. Lee, C. Wortmann, D. Holshouser, E.D. Nafziger, H. Kandel, J. Niekamp, W.J. Ross, J. Lofton, J. Vonk, K.L. Roozeboom, K.D. Thelen, L.E. Lindsey, M. Staton, S.L. Naeve, S.N. Casteel, W.J. Wiebold, S.P. Conley, Soybean response to nitrogen application across the United States: A synthesis-analysis, F. Crop. Res. 215 (2018) 74-82.

9. M. Li, R. Guo, Y. Jiao, X. Jin, H. Zhang, L. Shi, Comparison of Salt Tolerance in Soja Based on Metabolomics of Seedling Roots, Front. Plant Sci. 8 (2017).

10. Y. Jiao, Z. Bai, J. Xu, M. Zhao, Y. Khan, Y. Hu, L. Shi, Metabolomics and its physiological regulation process reveal the salt-tolerant mechanism in Glycine soja seedling roots, Plant Physiol. Biochem. (2018).

11. L. Yi, N. Dong, Y. Yun, B. Deng, D. Ren, S. Liu, Y. Liang, Chemometric methods in data processing of mass spectrometry-based metabolomics: A review, Anal. Chim. Acta. 914 (2016) 17-34.

12. M. Mulvaney, Carbon and Nitrogen Cycling under Conservation and Conventional Tillage in Peanut and Collard Agroecosystems,J.102 (2021).

13. P.O. Lim, H.J. Kim, H. Gil Nam, Leaf Senescence, Annu. Rev. Plant Biol. 58 (2007) 115-136.

14. R.E. Häusler, F. Ludewig, S. Krueger, Amino acids - A life between metabolism and signaling, Plant Sci. 229 (2014) 225-237.

15. W.L. Araújo, T. Tohge, K. Ishizaki, C.J. Leaver, A.R. Fernie, Protein degradation - an alternative respiratory substrate for stressed plants, Trends Plant Sci. 16 (2011) 489-498.

16. J. López-Bucio, M.F. Nieto-Jacobo, V. Ramírez-Rodríguez, L. Herrera-Estrella, Organic acid metabolism in plants: From adaptive physiology to transgenic varieties for cultivation in extreme soils, Plant Sci. 160 (2000) 1-13.

17. M. Tegeder, C. Masclaux-Daubresse, Source and sink mechanisms of nitrogen transport and use, New Phytol. 217 (2018) 35-53. 
18. J. Chen, Z. Hao, X. Guang, C. Zhao, P. Wang, L. Xue, Q. Zhu, L. Yang, Y. Sheng, Y. Zhou, H. Xu, H. Xie, X. Long, J. Zhang, Z. Wang, M. Shi, Y. Lu, S. Liu, L. Guan, Q. Zhu, L. Yang, S. Ge, T. Cheng, T. Laux, Q. Gao, Y. Peng, N. Liu, S. Yang, J. Shi, Liriodendron genome sheds light on angiosperm phylogeny and species-pair differentiation, Nat. Plants. (2018).

19. Y. Ohwaki, K. Sugahara, Active extrusion of protons and exudation of carboxylic acids in response to iron deficiency by roots of chickpea (Cicer arietinum L.), Plant Soil. 189 (1997) 49-55.

20. D. Liu, M. Li, Y. Liu, L. Shi, Integration of the metabolome and transcriptome reveals the resistance mechanism to low nitrogen in wild soybean seedling roots, Environ. Exp. Bot. 175 (2020) 104043.

21. J. Lecourt, V. Lauvergeat, N. Ollat, P. Vivin, S.J. Cookson, Shoot and root ionome responses to nitrate supply in grafted grapevines are rootstock genotype dependent, Aust. J. Grape Wine Res. 21 (2015) 311-318.

22. Y.F. Xue, S.C. Yue, Y.Q. Zhang, Z.L. Cui, X.P. Chen, F.C. Yang, I. Cakmak, S.P. McGrath, F.S. Zhang, C.Q. Zou, Grain and shoot zinc accumulation in winter wheat affected by nitrogen management, Plant Soil. 361 (2012) 153-163.

23. S. Zerche, K.T. Haensch, U. Druege, M.R. Hajirezaei, Nitrogen remobilisation facilitates adventitious root formation on reversible dark-induced carbohydrate depletion in Petunia hybrida, BMC Plant Biol. 16 (2016) 1-20.

24. H. Nayyar, R. Kaur, S. Kaur, R. Singh, Y-Aminobutyric Acid (GABA) Imparts Partial Protection from Heat Stress Injury to Rice Seedlings by Improving Leaf Turgor and Upregulating Osmoprotectants and Antioxidants, J. Plant Growth Regul. 33 (2014) 408-419.

25. M. Priya, L. Sharma, R. Kaur, H. Bindumadhava, R.M. Nair, K.H.M. Siddique, H. Nayyar, GABA (Y-aminobutyric acid), as a thermo-protectant, to improve the reproductive function of heat-stressed mungbean plants, Sci. Rep. 9 (2019) 1-15.

26. S. Ramesh, S. Tyerman, B. Xu, J. Bose, S. Kaur, V. Conn, P. Gonçalves, S. Lehre, S. Wege, S. Shabala, J. Feijó, P. Ryan, M. Gilliham, Corrigendum: GABA signalling modulates plant growth by directly regulating the activity of plant-specific anion transporters, Nat. Commun. 6 (2015) 78-79.

27. J.G. Streeter, D.G. Lohnes, R.J. Fioritto, Patterns of pinitol accumulation in soybean plants and relationships to droug[1] J.G. Streeter, D.G. Lohnes, R.J. Fioritto, Patterns of pinitol accumulation in soybean plants and relationships to drought tolerance, Plant, Cell Environ. 24 (2001) 429-438. , Plant, Cell Environ. 24 (2001) 429-438.

28. B.J. Shelp, A.W. Bown, M.D. McLean, Metabolism and functions of gamma-aminobutyric acid, Trends Plant Sci. 4 (1999) 446-452.

29. A.M. Kinnersley, F.J. Turano, Gamma aminobutyric acid (GABA) and plant responses to stress, CRC. Crit. Rev. Plant Sci. 19 (2000) 479-509.

30. B.J. Shelp, G.G. Bozzo, C.P. Trobacher, A. Zarei, K.L. Deyman, C.J. Brikis, Hypothesis/review: Contribution of putrescine to 4-aminobutyrate (GABA) production in response to abiotic stress, Plant Sci. 193-194 (2012) 130-135.

31. M.H. Nam, E. Bang, T.Y. Kwon, Y. Kim, E.H. Kim, K. Cho, W.J. Park, B.G. Kim, I.S. Yoon, Metabolite profiling of diverse rice germplasm and identification of conserved metabolic markers of rice roots in response to long-term mild salinity stress, Int. J. Mol. Sci. 16 (2015) 21959-21974.

32. H. Renault, V. Roussel, A. El Amrani, M. Arzel, D. Renault, A. Bouchereau, C. Deleu, The Arabidopsis pop2-1mutant reveals the involvement of GABA transaminase in salt stress tolerance, BMC Plant Biol. 10 (2010) 20.

33. J.M. Barbosa, N.K. Singh, J.H. Cherry, R.D. Locy, Nitrate uptake and utilization is modulated by exogenous $Y^{-}$ aminobutyric acid in Arabidopsis thaliana seedlings, Plant Physiol. Biochem. 48 (2010) 443-450.

34. K. Sita, V. Kumar, Role of Gamma Amino Butyric Acid (GABA) against abiotic stress tolerance in legumes: a review, Plant Physiol. Reports. 25 (2020) 654-663.

35. A.M. Kinnersley, F.J. Turano, Gamma Aminobutyric Acid ( GABA) and Plant Responses to Stress, Critical Reviews in Plant Sciences, 00(0):000-000 (2000).

36. C. Masclaux-Daubresse, F. Daniel-Vedele, J. Dechorgnat, F. Chardon, L. Gaufichon, A. Suzuki, Nitrogen uptake, assimilation and remobilization in plants: Challenges for sustainable and productive agriculture, Ann. Bot. 105 (2010)

Page $11 / 24$ 
$1141-1157$.

37. Y. Lu, H. Lam, E. Pi, Q. Zhan, S. Tsai, C. Wang, Y. Kwan, S. Ngai, Comparative metabolomics in Glycine max and Glycine soja under salt stress to reveal the phenotypes of their offspring, J. Agric. Food Chem. 61 (2013) 8711-8721.

38. J. López-Bucio, M.F. Nieto-Jacobo, V. Ramírez-Rodríguez, L. Herrera-Estrella, Organic acid metabolism in plants: From adaptive physiology to transgenic varieties for cultivation in extreme soils, Plant Sci. 160 (2000) 1-13.

39. T.M. Hildebrandt, A. Nunes Nesi, W.L. Araújo, H.P. Braun, Amino Acid Catabolism in Plants, Mol. Plant. 8 (2015) 15631579.

40. P.L. Gregersen, A. Culetic, L. Boschian, K. Krupinska, Plant senescence and crop productivity, Plant Mol. Biol. 82 (2013) 603-622.

41. B. Touraine, B. Muller, C. Grignon, Effect of Phloem-Translocated Malate on N03- Uptake by Roots of Intact Soybean Plants', (1992) 1118-1123.

42. D.P. Schachtman, R. Shin, Nutrient Sensing and Signaling: NPKS, Annu. Rev. Plant Biol. 58 (2007) 47-69.

43. M. Li, J. Xu, R. Guo, Y. Liu, S. Wang, H. Wang, A. Ullah, L. Shi, Identifying the metabolomics and physiological differences among Soja in the early flowering stage, Plant Physiol. Biochem. 139 (2019) 82-91.

44. C. Fritz, N. Palacios-Rojas, R. Feil, M. Stitt, Regulation of secondary metabolism by the carbon-nitrogen status in tobacco: Nitrate inhibits large sectors of phenylpropanoid metabolism, Plant J. 46 (2006) 533-548.

45. P. Geigenberger, S. Langenberger, I. Wilke, D. Heineke, H.W. Heldt, M. Stitt, Sucrose is metabolised by sucrose synthase and glycolysis within the phloem complex of Ricinus communis L. seedlings, Planta. 190 (1993) 446-453.

46. L. Avila-Ospina, G. Clément, C. Masclaux-Daubresse, Metabolite Profiling for Leaf Senescence in Barley Reveals Decreases in Amino Acids and Glycolysis Intermediates, Agronomy. 7 (2017) 15.

47. C.Y. Huang, U. Roessner, I. Eickmeier, Y. Genc, D.L. Callahan, N. Shirley, P. Langridge, A. Bacic, Metabolite profiling reveals distinct changes in carbon and nitrogen metabolism in phosphate-deficient barley plants (Hordeum vulgare L.), Plant Cell Physiol. 49 (2008) 691-703.

\section{Tables}

Table 1 Carbon and nitrogen contents in young and old leaves of two wild soybean varieties under LN stress

\begin{tabular}{|c|c|c|c|c|c|c|c|}
\hline & & \multicolumn{2}{|l|}{ GS1 } & \multicolumn{2}{|l|}{ GS2 } & \multicolumn{2}{|c|}{ Fold changes $\log _{2}(\mathrm{LN} / \mathrm{CK})$} \\
\hline & & CK & $\mathrm{LN}$ & CK & LN & GS1 & GS2 \\
\hline \multirow[t]{3}{*}{ YL } & TNख\%】 & $5.62 \pm 0.16$ & $5.13 \pm 0.25$ & $5.66 \pm 0.16$ & $6.16 \pm 0.02$ & -0.13 & 0.12 \\
\hline & $\mathrm{TC} \%$ & $40.61 \pm 1.19$ & $38.63 \pm 1.79$ & $40.44 \pm 1.36$ & $43.27 \pm 0.07$ & -0.07 & 0.10 \\
\hline & $\mathrm{C} / \mathrm{N}$ & $7.23 \pm 0.03$ & $7.54 \pm 0.03$ & $7.14 \pm 0.04$ & $7.03 \pm 0.02$ & 0.06 & -0.02 \\
\hline \multirow[t]{3}{*}{ OL } & TNख\%】 & $5.01 \pm 0.05$ & $3.94 \pm 0.14$ & $4.77 \pm 0.07$ & $4.38 \pm 0.05$ & $-0.35^{\star}$ & $-0.13^{\star}$ \\
\hline & $\mathrm{TC} \% \%$ & $40.36 \pm 0.06$ & $37.80 \pm 0.85$ & $40.26 \pm 1.24$ & $41.55 \pm 0.18$ & -0.1 & 0.05 \\
\hline & $\mathrm{C} / \mathrm{N}$ & $8.06 \pm 0.08$ & $9.60 \pm 0.14$ & $8.43 \pm 0.14$ & $9.5 \pm 0.09$ & $0.25^{\star}$ & $0.17^{*}$ \\
\hline
\end{tabular}

Values were presented as the mean \pm standard error of four biological replicates. GS1, common wild soybean, W, LNtolerant wild soybean, CK, control treatment, LN, low nitrogen stress, YL, young leaves, OL, old leaves, C/N, Carbon/Nitrogen, * indicate significant $(P<0.05)$ 
Table 2 lon contents in young and old leaves of two wild soybean ecotypes under LN stress 


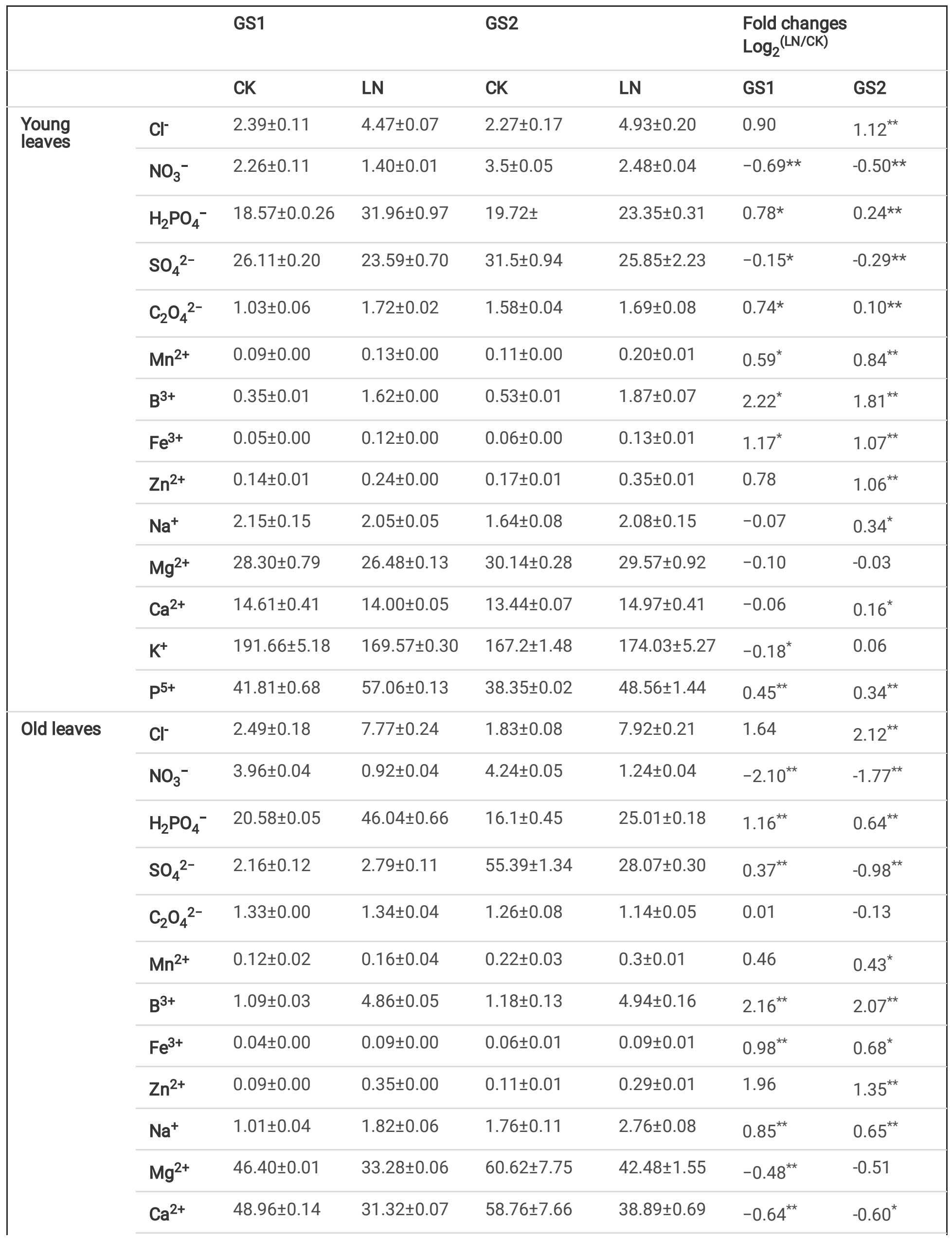




\begin{tabular}{lllllll|}
$\mathbf{K}^{+}$ & $163.44 \pm 0.07$ & $172.59 \pm 0.70$ & $166.64 \pm 17.11$ & $141.27 \pm 3.60$ & $0.08^{\star \star}$ & -0.24 \\
\hline $\mathbf{P}^{5+}$ & $32.87 \pm 0.12$ & $70.81 \pm 0.04$ & $26.61 \pm 3.01$ & $43.66 \pm 0.99$ & $1.11^{\star \star}$ & $0.71^{\star \star}$ \\
\hline
\end{tabular}

Values were presented as the mean \pm standard error of four biological replicates. GS1, common soybean, GS2, barren tolerant wild soybean, CK, control treatment, LN, low-N stress. * and ** indicate significant $(\mathrm{P}<0.05)$ and highly significant $(P<0.01)$ differences, respectively.

Table 3 Changes of LN stress on metabolite content in young leaves of two wild soybean ecotypes. 
Metabolite name Relative concentration

Fold changes

\begin{tabular}{|c|c|c|c|c|c|c|c|}
\hline & \multirow{2}{*}{\multicolumn{2}{|c|}{ GS1 }} & \multirow{2}{*}{\multicolumn{2}{|c|}{ GS2 }} & \multirow{2}{*}{\multicolumn{2}{|c|}{ Log2(LN/CK) }} \\
\hline & & & & & & & \\
\hline & & CK & $\mathrm{LN}$ & CK & $\mathrm{LN}$ & GS1 & GS2 \\
\hline \multirow[t]{18}{*}{ Amino acids } & Valine & $0.62 \pm 0.04$ & $0.54 \pm 0.05$ & $8.16 \pm 0.95$ & $7.05 \pm 0.29$ & $-0.19 \star \star$ & -0.21 \\
\hline & Isoleucine & $0.39 \pm 0.01$ & $0.11 \pm 0.00$ & $1.49 \pm 0.28$ & $2.76 \pm 0.20$ & $-1.83^{\star \star}$ & $0.89 *$ \\
\hline & Aspartic acid & $5.30 \pm 0.06$ & $9.35 \pm 0.01$ & $7.60 \pm 0.51$ & $11.39 \pm 0.34$ & $0.82^{\star \star}$ & $0.58^{\star \star}$ \\
\hline & Asparagine & $2.58 \pm 0.67$ & $0.60 \pm 0.76$ & $0.11 \pm 0.05$ & $0.09 \pm 0.01$ & $-2.09 * \star$ & -0.38 \\
\hline & L-Homoserine & $0.22 \pm 0.00$ & $0.08 \pm 0.00$ & $0.18 \pm 0.06$ & $0.99 \pm 0.03$ & -1.56 & $2.45^{\star \star}$ \\
\hline & L-Allothreonine & $1.77 \pm 0.03$ & $1.82 \pm 0.04$ & $2.44 \pm 0.15$ & $0.81 \pm 0.09$ & 0.04 & $-1.58^{\star \star}$ \\
\hline & Serine & $0.19 \pm 0.13$ & $0.16 \pm 0.25$ & $0.90 \pm 0.14$ & $0.68 \pm 0.07$ & -0.27 & 0.41 \\
\hline & Proline & $0.27 \pm 0.00$ & $0.21 \pm 0.02$ & $0.22 \pm 0.02$ & $0.50 \pm 0.03$ & $-0.40 *$ & $1.21^{\star \star}$ \\
\hline & Alanine & $0.06 \pm 0.04$ & $0.07 \pm 0.03$ & $5.05 \pm 0.36$ & $24.78 \pm 0.75$ & 0.35 & $2.29 \star \star$ \\
\hline & Glycine & $28.26 \pm 0.02$ & $50.61 \pm 0.04$ & $6.69 \pm 0.57$ & $4.58 \pm 0.27$ & $0.84^{*}$ & $-0.54^{\star}$ \\
\hline & Phenylalanine & $11.31 \pm 0.07$ & $10.73 \pm 0.02$ & $1.89 \pm 0.28$ & $0.69 \pm 0.13$ & -0.08 & $-1.45^{\star}$ \\
\hline & $\begin{array}{l}\text { 4-Aminobutyric } \\
\text { acid }\end{array}$ & $0.52 \pm 0.01$ & $0.32 \pm 0.03$ & $2.37 \pm 0.12$ & $2.73 \pm 0.28$ & $-0.70 *$ & 0.21 \\
\hline & Ethanolamine & $55.44 \pm 0.02$ & $86.12 \pm 0.04$ & $15.31 \pm 0.55$ & $8.50 \pm 0.35$ & $0.64^{\star}$ & $-0.85^{\star \star}$ \\
\hline & D-Mannosamine & $11.32 \pm 0.00$ & $7.19 \pm 0.01$ & $0.06 \pm 0.05$ & $0.08 \pm 0.01$ & -0.65 & 0.25 \\
\hline & Sphingosine & $1.76 \pm 0.30$ & $2.34 \pm 0.34$ & $3.08 \pm 0.32$ & $2.85 \pm 0.54$ & 0.41 & -0.11 \\
\hline & $\begin{array}{l}\text { 3- } \\
\text { Aminoisobutyric } \\
\text { acid }\end{array}$ & $0.41 \pm 0.02$ & $0.23 \pm 0.03$ & $0.24 \pm 0.02$ & $0.25 \pm 0.02$ & -0.85 & 0.08 \\
\hline & $\begin{array}{l}\text { 5-Aminovaleric } \\
\text { acid }\end{array}$ & $4.59 \pm 0.14$ & $0.80 \pm 0.09$ & $0.29 \pm 0.07$ & $0.62 \pm 0.08$ & -2.53 & $1.07 *$ \\
\hline & $\begin{array}{l}2- \\
\text { Hydroxypyridine }\end{array}$ & $0.07 \pm 0.00$ & $0.01 \pm 0.00$ & $7.20 \pm 0.62$ & $7.58 \pm 0.25$ & -2.32 & 0.07 \\
\hline \multirow{10}{*}{$\begin{array}{l}\text { Sugars and } \\
\text { polyols }\end{array}$} & Sucrose & $0.08 \pm 0.07$ & $0.07 \pm 0.00$ & $1.30 \pm 0.17$ & $5.28 \pm 0.44$ & -0.10 & $2.02^{\star \star}$ \\
\hline & Maltose & $0.33 \pm 0.01$ & $0.28 \pm 0.02$ & $0.30 \pm 0.04$ & $1.48 \pm 0.14$ & -0.21 & $2.33^{\star \star}$ \\
\hline & Maltotriose & $0.93 \pm 0.02$ & $0.96 \pm 0.03$ & $0.09 \pm 0.01$ & $0.05 \pm 0.03$ & 0.04 & -0.73 \\
\hline & Melezitose & $28.10 \pm 0.38$ & $20.39 \pm 0.02$ & $0.06 \pm 0.01$ & $1.29 \pm 0.25$ & -0.46 & $4.55^{\star \star}$ \\
\hline & Threitol & $2.57 \pm 0.20$ & $1.72 \pm 0.08$ & $0.29 \pm 0.01$ & $1.17 \pm 0.16$ & -0.58 & $2.04^{\star \star}$ \\
\hline & Galactinol & $0.71 \pm 0.01$ & $0.52 \pm 0.02$ & $0.92 \pm 0.09$ & $1.03 \pm 0.03$ & -0.47 & 0.16 \\
\hline & Glycerol & $1.91 \pm 0.28$ & $1.56 \pm 0.27$ & $8.33 \pm 0.27$ & $6.66 \pm 0.82$ & -0.29 & -0.32 \\
\hline & Myo-Inositol & $0.31 \pm 0.02$ & $0.22 \pm 0.03$ & $43.71 \pm 0.55$ & $2.15 \pm 0.33$ & -0.48 & $-4.35^{\star \star}$ \\
\hline & L-Threose & $54.13 \pm 0.01$ & $60.66 \pm 0.16$ & $0.08 \pm 0.01$ & $0.02 \pm 0.01$ & 0.16 & $-1.67 \star \star$ \\
\hline & Xylose & $0.09 \pm 0.02$ & $0.11 \pm 0.01$ & $1.32 \pm 0.18$ & $1.37 \pm 0.25$ & 0.29 & 0.05 \\
\hline
\end{tabular}




\begin{tabular}{|c|c|c|c|c|c|c|c|}
\hline & Cellobiose & $0.98 \pm 0.06$ & $0.60 \pm 0.02$ & $0.04 \pm 0.01$ & $0.31 \pm 0.04$ & $(0.72)$ & $2.83^{\star *}$ \\
\hline & Lactulose & $1.95 \pm 0.12$ & $0.05 \pm 0.03$ & $0.33 \pm 0.04$ & $1.71 \pm 0.47$ & $(5.28)$ & $2.39 *$ \\
\hline & D-Arabitol & $0.25 \pm 0.13$ & $0.97 \pm 0.06$ & $2.28 \pm 0.36$ & $1.18 \pm 0.09$ & 1.96 & $0.95^{\star}$ \\
\hline & $\begin{array}{l}\text { Glucose-6- } \\
\text { Phosphate }\end{array}$ & $306.86 \pm 0.34$ & $216.33 \pm 0.17$ & $0.03 \pm 0.00$ & $0.03 \pm 0.00$ & $-0.50 *$ & 0.33 \\
\hline & $\begin{array}{l}\text { Fructose 2,6- } \\
\text { Biphosphate }\end{array}$ & $0.08 \pm 0.00$ & $0.28 \pm 0.01$ & $0.15 \pm 0.02$ & $0.07 \pm 0.02$ & $1.84^{\star \star}$ & $-1.12^{\star}$ \\
\hline & Maltose & $1.50 \pm 0.22$ & $2.40 \pm 0.25$ & $0.25 \pm 0.02$ & $0.61 \pm 0.14$ & 0.68 & $1.30 *$ \\
\hline \multirow[t]{25}{*}{ Organic acid } & Glycolic acid & $8.09 \pm 0.33$ & $4.01 \pm 0.07$ & $0.12 \pm 0.00$ & $0.74 \pm 0.19$ & -1.01 & $2.67^{\star}$ \\
\hline & Lactic acid & $0.15 \pm 0.02$ & $0.16 \pm 0.04$ & $2.97 \pm 0.38$ & $3.47 \pm 0.14$ & 0.09 & 0.22 \\
\hline & $\begin{array}{l}\text { Methylmalonic } \\
\text { acid }\end{array}$ & $0.55 \pm 0.08$ & $0.06 \pm 0.01$ & $0.12 \pm 0.00$ & $0.08 \pm 0.01$ & -3.13 & $-0.57^{\star}$ \\
\hline & Mucic acid & $0.20 \pm 0.02$ & $0.13 \pm 0.02$ & $1.45 \pm 0.16$ & $1.84 \pm 0.09$ & -0.64 & 0.34 \\
\hline & D-Glyceric acid & $0.33 \pm 0.55$ & $0.43 \pm 0.09$ & $2.52 \pm 0.25$ & $1.81 \pm 0.52$ & 0.36 & -0.47 \\
\hline & Pyruvic acid & $0.20 \pm 0.55$ & $0.13 \pm 0.30$ & $1.93 \pm 0.08$ & $4.41 \pm 0.50$ & $-0.64^{\star}$ & 1.19 ** \\
\hline & Succinic acid & $0.25 \pm 0.02$ & $0.32 \pm 0.02$ & $6.97 \pm 0.69$ & $6.53 \pm 0.48$ & $0.37 *$ & -0.09 \\
\hline & Fumaric acid & $4.50 \pm 0.25$ & $2.40 \pm 0.16$ & $3.08 \pm 0.04$ & $25.36 \pm 1.99$ & $-0.91^{\star}$ & $3.04^{\star \star}$ \\
\hline & Citramalic acid & $7.06 \pm 0.3$ & $1.09 \pm 0.02$ & $0.45 \pm 0.02$ & $0.18 \pm 0.04$ & $-2.70 * \star$ & $-1.31^{\star \star *}$ \\
\hline & Oxalic acid & $0.97 \pm 1.79$ & $0.78 \pm 0.03$ & $0.24 \pm 0.02$ & $0.17 \pm 0.03$ & -0.31 & -0.49 \\
\hline & Itaconic acid & $2.90 \pm 0.03$ & $3.91 \pm 1.79$ & $3.07 \pm 0.35$ & $2.33 \pm 0.34$ & 0.43 & -0.40 \\
\hline & Malonic acid & $4.47 \pm 0.08$ & $5.48 \pm 0.51$ & $1.12 \pm 0.06$ & $9.71 \pm 0.55$ & 0.30 & $3.12^{\text {** }}$ \\
\hline & Maleic acid & $0.08 \pm 0.03$ & $0.18 \pm 0.03$ & $6.99 \pm 0.39$ & $9.24 \pm 0.90$ & $1.11^{*}$ & 0.40 \\
\hline & Gluconic acid & $0.56 \pm 0.07$ & $0.78 \pm 0.09$ & $0.07 \pm 0.00$ & $0.08 \pm 0.02$ & $0.49 * \star$ & 0.16 \\
\hline & Nicotinic acid & $4.95 \pm 0.58$ & $10.38 \pm 0.40$ & $0.69 \pm 0.04$ & $1.25 \pm 0.15$ & $1.07^{* \star}$ & $0.85^{\star}$ \\
\hline & Threonic acid & $2.23 \pm 0.83$ & $0.72 \pm 0.00$ & $1.44 \pm 0.21$ & $0.81 \pm 0.14$ & $-1.63^{\star}$ & -0.84 \\
\hline & Galactonic acid & $0.83 \pm 0.00$ & $0.51 \pm 0.10$ & $1.01 \pm 0.04$ & $1.12 \pm 0.08$ & $-0.70 * \star$ & 0.15 \\
\hline & $\begin{array}{l}\text { Glucoheptonic } \\
\text { acid }\end{array}$ & $16.23 \pm 0.31$ & $8.81 \pm 0.41$ & $0.22 \pm 0.03$ & $0.56 \pm 0.02$ & -0.88 & $1.37^{\star \star}$ \\
\hline & $\begin{array}{l}\text { 3- } \\
\text { Hydroxypropionic } \\
\text { acid }\end{array}$ & $0.04 \pm 0.00$ & $0.04 \pm 0.00$ & $0.19 \pm 0.01$ & $0.14 \pm 0.01$ & -0.14 & -0.40 \\
\hline & Shikimic acid & $0.01 \pm 0.00$ & $0.00 \pm 0.00$ & $3.90 \pm 0.21$ & $1.92 \pm 0.49$ & -1.87 & $-1.02^{\star}$ \\
\hline & Stearic acid & $0.24 \pm 0.01$ & $0.11 \pm 0.03$ & $0.24 \pm 0.02$ & $0.30 \pm 0.03$ & $-1.18^{\star}$ & 0.35 \\
\hline & Palmitic acid & $42.32 \pm 1.77$ & $40.01 \pm 1.53$ & $0.32 \pm 0.06$ & $0.44 \pm 0.14$ & -0.08 & 0.48 \\
\hline & Linolenic acid & $0.17 \pm 0.05$ & $0.14 \pm 0.02$ & $1.53 \pm 0.12$ & $0.18 \pm 0.02$ & -0.29 & -3.06 ** \\
\hline & Linoleic acid & $4.13 \pm 0.09$ & $2.72 \pm 0.13$ & $1.82 \pm 0.40$ & $2.34 \pm 0.19$ & $-0.60 * \star$ & 0.37 \\
\hline & Ferulic acid & $13.46 \pm 0.03$ & $36.23 \pm 0.13$ & $1.58 \pm 0.26$ & $0.90 \pm 0.12$ & $1.43^{\star \star}$ & -0.81 \\
\hline
\end{tabular}




\begin{tabular}{llllllll} 
& Salicylic acid & $0.13 \pm 0.34$ & $0.18 \pm 0.13$ & $0.39 \pm 0.03$ & $0.05 \pm 0.02$ & 0.52 & $-2.94^{\star *}$ \\
\cline { 2 - 8 } & Caffeic acid & $1.30 \pm 0.00$ & $0.36 \pm 0.00$ & $0.02 \pm 0.00$ & $0.01 \pm 0.00$ & $-1.86^{\star}$ & -0.96 \\
\hline \multirow{2}{*}{ Phenylpropion } & Neohesperidin & $11.03 \pm 0.05$ & $7.74 \pm 0.21$ & $0.15 \pm 0.02$ & $1.02 \pm 0.84$ & $-0.51^{\star}$ & 2.78 \\
\cline { 2 - 8 } & Prunin & $8.47 \pm 1.06$ & $13.32 \pm 0.36$ & $0.09 \pm 0.01$ & $0.23 \pm 0.02$ & $0.65^{\star *}$ & $1.37^{\star *}$
\end{tabular}

Values were presented as the mean \pm standard error of four biological replicates. GS1, common soybean, GS2, barren tolerant wild soybean, CK, control treatment, LN, low-N stress. * and ** indicate significant $(P<0.05)$ and highly significant $(P<0.01)$ differences, respectively.

Table 4 Changes of LN stress on metabolite content in old leaves of two wild soybean ecotypes. 


\begin{tabular}{|c|c|c|c|c|c|c|c|}
\hline & \multirow[t]{3}{*}{ Metabolite name } & \multicolumn{4}{|c|}{ Relative concentration } & \multirow{2}{*}{\multicolumn{2}{|c|}{$\begin{array}{l}\text { Fold changes } \\
\text { Log2(LN/CK) }\end{array}$}} \\
\hline & & \multicolumn{2}{|l|}{ GS1 } & \multicolumn{2}{|l|}{ GS2 } & & \\
\hline & & CK & LN & CK & LN & GS1 & GS2 \\
\hline \multirow[t]{18}{*}{ Amino acids } & L-Proline & $0.11 \pm 0.01$ & $0.81 \pm 0.18$ & $1.47 \pm 0.27$ & $0.66 \pm 0.08$ & $-1.17^{\star \star}$ & $2.85^{\star \star}$ \\
\hline & Glycine & $1.07 \pm 0.15$ & $1.27 \pm 0.30$ & $0.08 \pm 0.02$ & $0.04 \pm 0.01$ & $-0.74^{\star}$ & 0.25 \\
\hline & Sarcosine & $0.81 \pm 0.15$ & $2.97 \pm 0.63$ & $0.20 \pm 0.04$ & $0.14 \pm 0.00$ & $-0.58^{\star}$ & $1.88^{*}$ \\
\hline & L-Homoserine & $1.04 \pm 0.21$ & $2.42 \pm 0.26$ & $0.19 \pm 0.01$ & $0.15 \pm 0.00$ & $-0.34^{\star \star}$ & $1.22^{\star *}$ \\
\hline & L-Aspartic acid & $0.07 \pm 0.04$ & $0.33 \pm 0.09$ & $0.21 \pm 0.01$ & $0.19 \pm 0.01$ & $-0.15^{\star}$ & $2.28^{\star}$ \\
\hline & L-Alanine & $0.09 \pm 0.01$ & $0.26 \pm 0.03$ & $0.02 \pm 0.01$ & $0.03 \pm 0.00$ & 0.05 & $1.57^{\star \star}$ \\
\hline & L-Asparagine & $0.06 \pm 0.01$ & $0.22 \pm 0.05$ & $0.10 \pm 0.01$ & $0.11 \pm 0.01$ & $0.21^{*}$ & $1.95^{\star}$ \\
\hline & L-Valine & $37.13 \pm 3.86$ & $47.46 \pm 5.60$ & $2.11 \pm 0.32$ & $2.43 \pm 0.95$ & 0.20 & 0.35 \\
\hline & Cycloleucine & $30.89 \pm 5.31$ & $44.38 \pm 8.78$ & $0.50 \pm 0.17$ & $0.64 \pm 0.33$ & 0.33 & 0.52 \\
\hline & L-Isoleucine & $0.38 \pm 0.01$ & $1.33 \pm 0.25$ & $0.22 \pm 0.05$ & $0.30 \pm 0.25$ & 0.44 & $1.79 * \star$ \\
\hline & Beta-Alanine & $0.13 \pm 0.04$ & $0.07 \pm 0.02$ & $0.06 \pm 0.02$ & $0.08 \pm 0.05$ & 0.55 & -1.02 \\
\hline & L-Phenylalanine & $0.08 \pm 0.03$ & $0.17 \pm 0.02$ & $0.15 \pm 0.02$ & $0.23 \pm 0.06$ & $0.62^{*}$ & $1.01^{*}$ \\
\hline & L-Serine & $0.01 \pm 0.00$ & $0.06 \pm 0.01$ & $8.47 \pm 2.47$ & $15.09 \pm 4.34$ & $0.83^{*}$ & $2.32^{\star}$ \\
\hline & Threonine & $0.02 \pm 0.00$ & $0.03 \pm 0.01$ & $0.05 \pm 0.01$ & $0.10 \pm 0.06$ & 0.89 & $0.97 *$ \\
\hline & Sphingosine & $6.28 \pm 2.67$ & $0.42 \pm 0.39$ & $0.56 \pm 0.49$ & $0.64 \pm 0.45$ & 0.18 & $-3.92^{\star \star}$ \\
\hline & $\begin{array}{l}\text { Gamma- } \\
\text { Aminobutyric acid }\end{array}$ & $0.10 \pm 0.02$ & $0.19 \pm 0.02$ & $0.34 \pm 0.03$ & $0.41 \pm 0.03$ & $0.27 *$ & $0.92^{\star}$ \\
\hline & Ethanolamine & $30.85 \pm 6.18$ & $61.33 \pm 6.31$ & $0.57 \pm 0.28$ & $1.16 \pm 1.26$ & 1.01 & $0.99 *$ \\
\hline & $\begin{array}{l}\text { 5-Aminopentanoic } \\
\text { acid }\end{array}$ & $0.73 \pm 0.30$ & $0.03 \pm 0.02$ & $0.00 \pm 0.00$ & $0.01 \pm 0.01$ & 2.63 & $-4.75^{\star \star}$ \\
\hline \multirow{9}{*}{$\begin{array}{l}\text { Sugar and } \\
\text { polyols }\end{array}$} & D-Galactose & $0.05 \pm 0.01$ & $0.08 \pm 0.01$ & $0.03 \pm 0.02$ & $0.00 \pm 0.00$ & $-2.58^{\star}$ & 0.53 \\
\hline & Lactose & $0.21 \pm 0.15$ & $0.03 \pm 0.02$ & $0.08 \pm 0.01$ & $0.04 \pm 0.03$ & -0.94 & -2.82 \\
\hline & Gluconic acid & $0.10 \pm 0.16$ & $0.34 \pm 0.08$ & $0.02 \pm 0.01$ & $0.01 \pm 0.01$ & -0.68 & $1.83^{\star}$ \\
\hline & L-Threose & $4.15 \pm 0.23$ & $4.96 \pm 0.75$ & $0.01 \pm 0.00$ & $0.01 \pm 0.00$ & 0.03 & 0.26 \\
\hline & Maltose & $0.12 \pm 0.01$ & $0.22 \pm 0.05$ & $0.25 \pm 0.05$ & $0.28 \pm 0.19$ & 0.13 & 0.91 \\
\hline & Xylose & $6.36 \pm 0.17$ & $10.71 \pm 2.81$ & $0.05 \pm 0.02$ & $0.06 \pm 0.05$ & 0.26 & 0.75 \\
\hline & Sucrose & $30.81 \pm 9.34$ & $2.64 \pm 0.02$ & $0.93 \pm 0.32$ & $1.50 \pm 0.43$ & 0.69 & $-3.54^{\star}$ \\
\hline & Glycerol & $0.10 \pm 0.01$ & $0.20 \pm 0.00$ & $0.02 \pm 0.00$ & $0.03 \pm 0.02$ & 0.89 & $0.95^{\star \star}$ \\
\hline & D-Arabitol & $0.12 \pm 0.01$ & $0.57 \pm 0.10$ & $0.48 \pm 0.08$ & $3.02 \pm 2.41$ & 2.64 & $2.23^{\star *}$ \\
\hline \multirow[t]{2}{*}{ Organic acids } & Malonic acid & $0.94 \pm 0.25$ & $0.46 \pm 0.17$ & $0.90 \pm 0.31$ & $0.76 \pm 0.15$ & -0.23 & $-1.04^{*}$ \\
\hline & Palmitic acid & $0.27 \pm 0.02$ & $0.82 \pm 0.26$ & $0.04 \pm 0.01$ & $0.02 \pm 0.00$ & $-1.20 *$ & 1.59 \\
\hline
\end{tabular}




\begin{tabular}{|c|c|c|c|c|c|c|c|}
\hline & Stearic acid & $1.92 \pm 0.10$ & $3.50 \pm 0.53$ & $0.24 \pm 0.01$ & $0.19 \pm 0.01$ & $-0.33^{* *}$ & $0.87 *$ \\
\hline & Pelargonic acid & $0.02 \pm 0.00$ & $0.02 \pm 0.00$ & $0.01 \pm 0.00$ & $0.01 \pm 0.00$ & $-0.22^{\star \star}$ & $0.27^{\star}$ \\
\hline & Linoleic acid & $8.30 \pm 2.49$ & $22.03 \pm 0.87$ & $0.00 \pm 0.00$ & $0.00 \pm 0.00$ & $-0.15^{\star \star}$ & $1.41^{\star \star}$ \\
\hline & Linolenic acid & $3.19 \pm 0.40$ & $2.49 \pm 0.33$ & $20.27 \pm 5.49$ & $21.56 \pm 6.58$ & 0.09 & -0.36 \\
\hline & $\begin{array}{l}\text { Fructose- } \\
6 \text {-biphosphate }\end{array}$ & $0.06 \pm 0.00$ & $0.15 \pm 0.01$ & $0.07 \pm 0.02$ & $0.04 \pm 0.00$ & $-0.72^{\star}$ & $1.25^{\star \star}$ \\
\hline & Pyruvic acid & $0.34 \pm 0.08$ & $0.85 \pm 0.11$ & $0.02 \pm 0.00$ & $0.03 \pm 0.00$ & $0.94 \star \star$ & $1.31^{\star}$ \\
\hline & $\begin{array}{l}\text { Glucose 6- } \\
\text { phosphate }\end{array}$ & $0.95 \pm 0.15$ & $1.55 \pm 0.22$ & $0.02 \pm 0.02$ & $0.09 \pm 0.05$ & $1.88^{\star}$ & 0.70 \\
\hline & Fumaric acid & $0.06 \pm 0.02$ & $0.07 \pm 0.01$ & $0.08 \pm 0.00$ & $0.06 \pm 0.03$ & -0.52 & 0.11 \\
\hline & L-Malic acid & $3.39 \pm 0.57$ & $5.29 \pm 1.30$ & $0.15 \pm 0.00$ & $0.21 \pm 0.00$ & $0.45^{\star \star}$ & 0.64 \\
\hline & Succinic acid & $6.33 \pm 1.30$ & $10.06 \pm 0.74$ & $1.07 \pm 0.29$ & $2.24 \pm 0.43$ & $1.07^{\star \star}$ & $0.67^{*}$ \\
\hline & Itaconic acid & $0.66 \pm 0.18$ & $0.09 \pm 0.02$ & $0.08 \pm 0.01$ & $0.08 \pm 0.02$ & -0.05 & $-2.91 * \star$ \\
\hline & L-Lactic acid & $0.69 \pm 0.09$ & $0.93 \pm 0.17$ & $0.07 \pm 0.00$ & $0.08 \pm 0.00$ & $0.09^{\star *}$ & 0.44 \\
\hline & Maleic acid & $1.73 \pm 0.60$ & $9.20 \pm 7.08$ & $1.73 \pm 0.55$ & $2.61 \pm 0.38$ & $0.59 *$ & 2.41 \\
\hline & Caffeic acid & $6.48 \pm 0.68$ & $5.12 \pm 0.54$ & $0.03 \pm 0.01$ & $0.05 \pm 0.00$ & $0.67 *$ & -0.34 \\
\hline & Glycolic acid & $0.28 \pm 0.05$ & $0.12 \pm 0.04$ & $0.12 \pm 0.03$ & $0.28 \pm 0.06$ & $1.25^{\star \star}$ & $-1.22^{\star \star}$ \\
\hline & Galactaric acid & $1.05 \pm 0.70$ & $1.42 \pm 0.27$ & $0.62 \pm 0.22$ & $1.49 \pm 0.55$ & $1.26^{*}$ & 0.44 \\
\hline & Benzoic acid & $0.03 \pm 0.00$ & $0.02 \pm 0.00$ & $0.01 \pm 0.01$ & $0.14 \pm 0.07$ & $3.37 *$ & -0.34 \\
\hline & Glyceric acid & $9.87 \pm 0.91$ & $15.71 \pm 2.56$ & $0.00 \pm 0.00$ & $0.00 \pm 0.00$ & $4.19^{\star}$ & $0.67^{\star}$ \\
\hline & Shikimic acid & $0.08 \pm 0.00$ & $0.15 \pm 0.02$ & $0.19 \pm 0.01$ & $0.15 \pm 0.09$ & -0.42 & $0.87^{* \star}$ \\
\hline & Ferulic acid & $0.47 \pm 0.04$ & $0.31 \pm 0.03$ & $0.06 \pm 0.04$ & $0.16 \pm 0.11$ & 1.35 & $-0.61^{\star \star}$ \\
\hline & Salicylic acid & $2.28 \pm 0.24$ & $7.70 \pm 1.42$ & $0.02 \pm 0.00$ & $0.02 \pm 0.02$ & 0.39 & $1.76^{\star \star}$ \\
\hline Phenylpropion & Prunin & $2.41 \pm 0.51$ & $5.61 \pm 0.19$ & $0.04 \pm 0.01$ & $0.02 \pm 0.02$ & -0.82 & $1.22^{\star}$ \\
\hline & Neohesperidin & $0.17 \pm 0.03$ & $1.27 \pm 0.24$ & $0.20 \pm 0.11$ & $0.29 \pm 0.38$ & 0.57 & $2.90^{\star \star}$ \\
\hline & Vanillin & $0.01 \pm 0.00$ & $0.33 \pm 0.26$ & $0.73 \pm 0.85$ & $1.81 \pm 0.84$ & 1.32 & 5.36 \\
\hline
\end{tabular}

Values were presented as the mean \pm standard error of four biological replicates. GS1, common soybean, GS2, barren tolerant wild soybean, CK, control treatment, $\mathrm{LN}$, low-N stress. * and ** indicate significant $(\mathrm{P}<0.05)$ and highly significant $(P<0.01)$ differences, respectively.

\section{Figures}



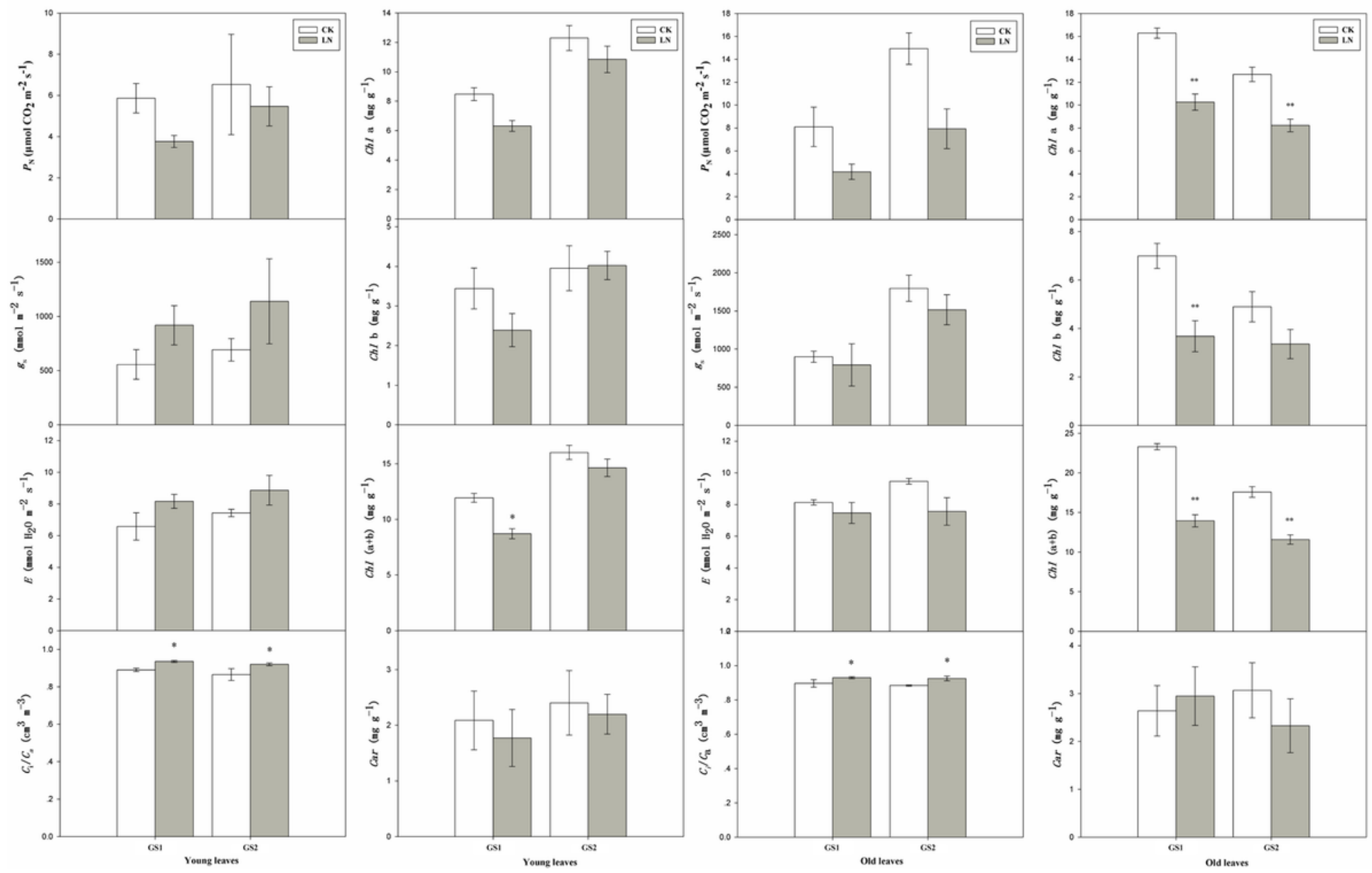

Figure 1

Growth performance of the two soybean ecotypes under control and LN-stress conditions. GS1, common soybean, GS2, barren tolerant wild soybean. CK, control treatment, LN, low-nitrogen stress.
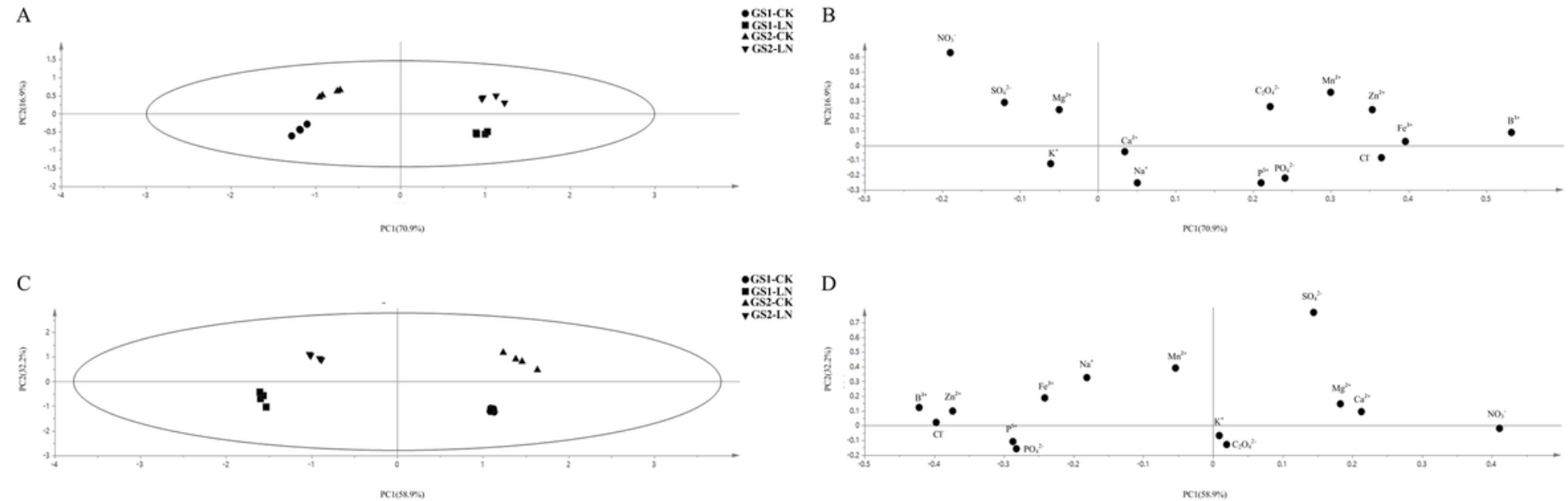

\section{Figure 2}

The changes in gas exchange of the two soybean ecotypes young and old leaves. (A) young leaves net photosynthetic rate(PN), (B) young leaves stomatal conductance(gs), (C) young leaves transpiration rate (E), (D) young leaves ratio of sub-stomatal to atmospheric $\mathrm{CO} 2$ concentrations(Ci/Ca), (A) old leaves net photosynthetic rate(PN), (B) old leaves stomatal conductance(gs), (C) old leaves transpiration rate (E), (D) old leaves ratio of sub-stomatal to atmospheric CO2 
concentrations(Ci/Ca), GS1, common soybean, GS2, barren tolerant wild soybean. CK, control treatment, LN, low-nitrogen stress, * indicate significant $(P<0.05)$.

\section{A}

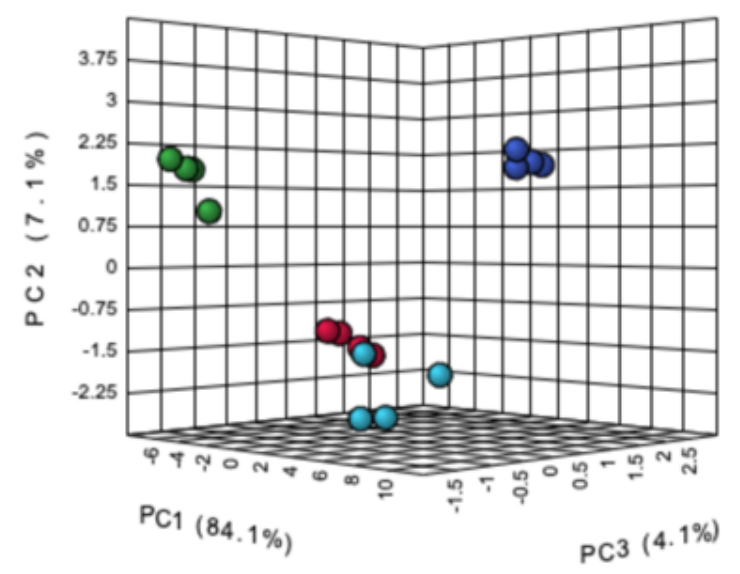

B

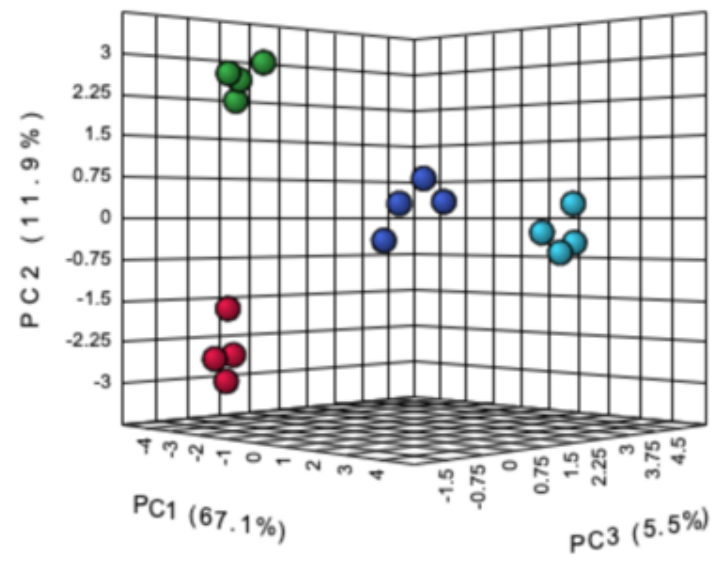

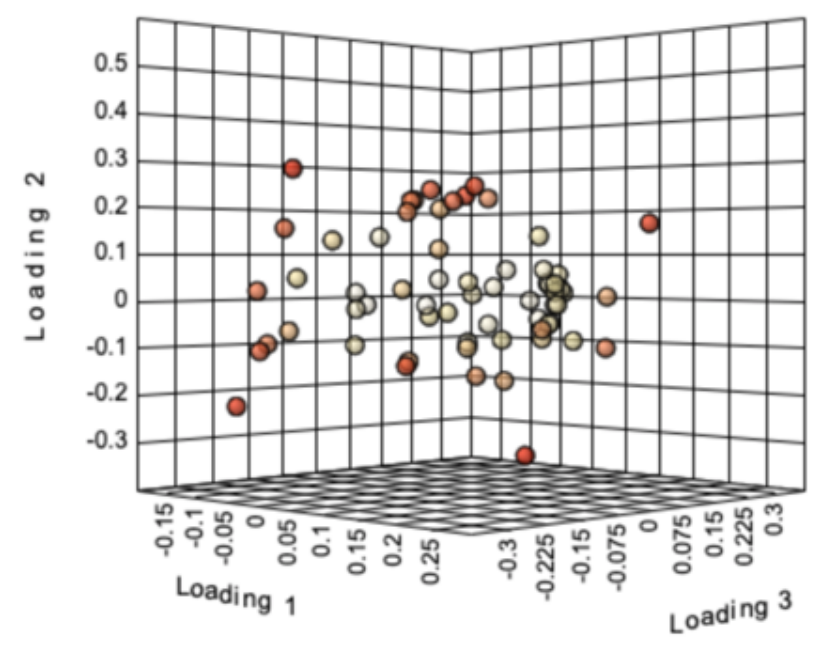

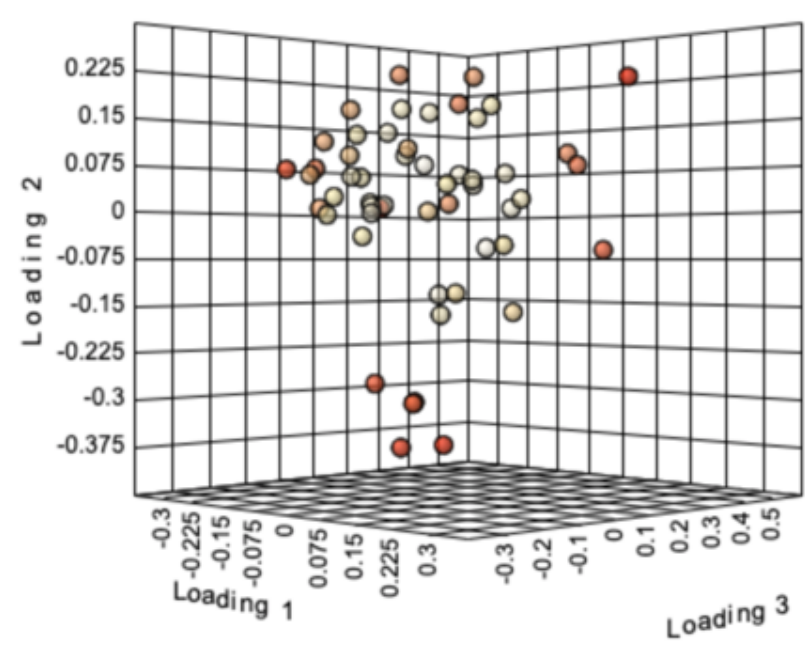

Figure 3

PCA of ionomic profiles and loading plots of ionomics in young and old leaves. (A) PCA of young and old leaves, (B) loading plot of young and old leaves, GS1, common soybean, GS2, barren tolerant wild soybean, YL, young leaves, OL, old leaves, CK, control treatment, LN, low-nitrogen stress. 


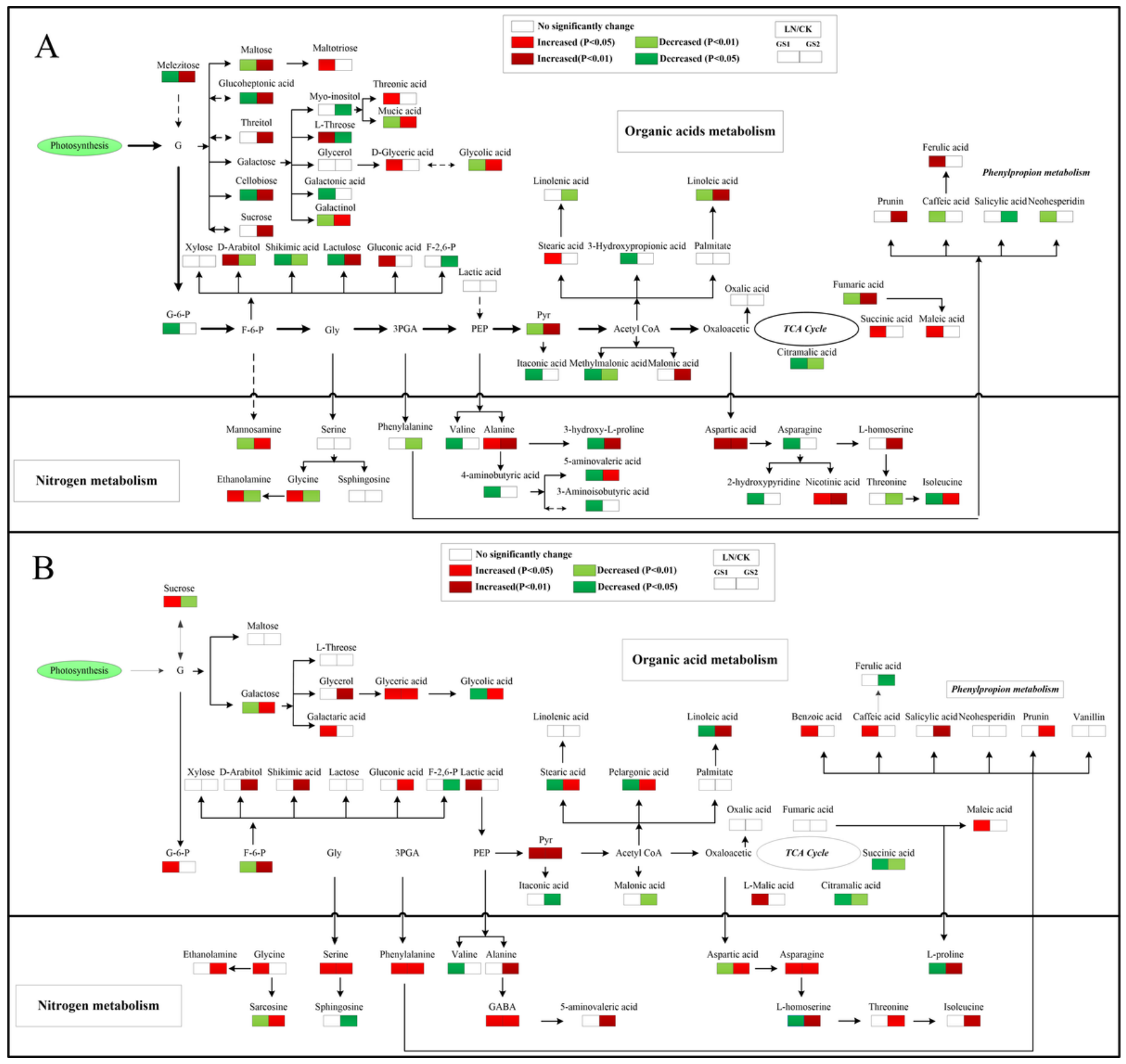

Figure 4

PCA of metabolic profiles and loading plots of metabolites in young and old leaves. (A) PCA of young leaves, (B) PCA of old leaves, (C) loading plot of young leaves, (D) loading plot of old leaves. GS1, common soybean, GS2, barren tolerant wild soybean, CK, control treatment, LN, low-nitrogen stress.

\section{Image not available with this version}

Figure 5 
Changes in the metabolic pathways of young and old leaves in the two soybean ecotypes. Suggested changes in the metabolic network in soybean seedlings under LN-stress conditions based on a partial least square-discriminant analysis (PLS-DA). (A) pathway of young leaves; (B) pathway of old leaves. GS1, common soybean; GS2, barren tolerant wild soybean; CK, control treatment; LN, low-nitrogen stress.

\section{Supplementary Files}

This is a list of supplementary files associated with this preprint. Click to download.

- S.table1.xlsx

- S.table2.xlsx

- S.table3.xlsx

- S.table4.xlsx 